\title{
EVALUATION OF INTRAOCULAR PRESSURE AND CENTRAL CORNEAL THICKNESS CHANGES AFTER HEMODIALYSIS IN PATIENTS WITH CHRONIC RENAL FAILURE
}

Seyfettin Erdem ( $\nabla$ serdem2147@hotmail.com )

Bismil State Hospital https://orcid.org/0000-0001-5742-1293

Muslum Gunes

Cınar State Hospital

\section{Research Article}

Keywords: Hemodialysis, Intraocular pressure, Central Corneal thickness

Posted Date: February 14th, 2019

DOI: https://doi.org/10.21203/rs.2.332/v1

License: (c) (i) This work is licensed under a Creative Commons Attribution 4.0 International License. Read Full License 


\section{Abstract}

Background: This study evaluated short-term changes in intraocular pressure (IOP) and corneal thickness (CCT) following haemodialysis (HD) in chronic renal failure (CRF) patients.

Methods: We studied 34 eyes of 34 patients with CRF undergoing HD. Patients included in the study were classified into two subgroups: group 1 (with DM) and group 2 (non DM). All patients underwent a detailed ophthalmological examination including CCT and IOP before and after the HD session. Total body weight and body volume loss after haemodialysis were also measured.

Results: The sex distribution of patients were 22 female (64.7\%) and 12 male (35.3\%). The DM group was comprised of 19 patients (55.9\%), and the non-DM had 15 (44.1\%). The mean age was $60.3 \pm 17.2$ (range 21-88) years, and the dialysis time was $51.4 \pm 38.5$ (range 5-132) months. The mean IOP change after $\mathrm{HD}$ decreased from $15.88 \pm 2.37$ to $14.11 \pm 2.02 \mathrm{mmHg}(95 \% \mathrm{Cl}, 1.40-2.11 ; \mathrm{p}<0.001)$. The mean CCT decreased from $554.88 \pm 14.27$ to $550.52 \pm 13.67 \mu \mathrm{m}$. $(95 \% \mathrm{Cl}, 1.97-4.08 ; P=\mathrm{p}<0.001)$. The loss in body volume was positively correlated with a decrease in IOP $(r=0.737, p<0.001)$ and CCT $(r=0.784, p<$ $0.001)$.

Conclusions: In patients with CRF who have glaucoma, visual acuity may be adversely affected by IOP and CCT changes following HD. Therefore, a detailed ophthalmologic examination should be performed to take preventive measures for at-risk patients before and after HD.

Keywords: Hemodialysis, Intraocular pressure, Central Corneal thickness.

\section{Background}

During haemodialysis (HD), diffusion eliminates osmotically active materials, resulting in a body fluid loss and reduced blood osmolarity [1]. Consequently, these changes can affect ocular parameters such as central corneal thickness (CTT) and intraocular pressure (IOP).

Both the uremic state and dialysis procedure itself can cause several ocular abnormalities in patients with chronic renal failure (CRF) undergoing HD [2, 3]. CRF patients treated with HD have various ophthalmologic findings such as increased tear osmolarity, dry eyes and corneal endothelium changes. $[4,5]$. In CRF patients, posterior segment findings such as retinopathy and neuropathy may be seen depending on both HT and DM. [6, 7].

Systemic hemodynamic parameters, as well as eye fluid volume and composition, can change with HD. There are many studies examining the anterior and posterior segment showed significant changes in IOP and $\mathrm{CC}$ [8-12]. Given the contradictory reports of HD affecting IOP, precise and mechanistic insights of HD on IOP are not well-established $[11,13,14]$. If the CCT values are above or below normal, they lead to an incorrect evaluation of IOP values. 
Therefore, this study aimed to evaluate IOP changes after HD sessions. We also aim to demonstrate the possible association between IOP, CRF, total body volume losses, and serum osmolality. We

\section{Methods}

We performed this prospective cross-sectional study in the ophthalmology outpatient clinic of our hospital. We performed the study after the approval of the ethics committee of Gazi Yasargil Training and Research Hospital (decision \# 2018/84). And our study was performed according to the Declaration of Helsinki. We received written informed consent from all patiens before including in the study.

In total, we examined the right eyes of 34 chronic renal failure patients undergoing HD in the Dialysis Unit of our Hospital. Patients included in the study were classified into two subgroups: group 1 (with DM, 15 patients) and group 2 (non DM, 19 patients). All subjects underwent haemodialysis sessions three to four times a week on average using high performance dialysis devices with a blood circulation rate of $250 \mathrm{ml}$ / min. Patients who had visual acuity over 20/200 and had received HD treatment in the morning sessions for at least three months were included in this study. Patients with corneal haze, history of ocular surgery in the previous three months, history of glaucoma, laser photocoagulation, or ocular trauma were excluded from the study.

All patients underwent a detailed ophthalmological examination including CCT and IOP before and after the HD session. Anterior and posterior segments were examined with slit-lamp biomicroscopy. Bestcorrected visual acuity was measured with a Snellen chart. IOP was measured by Goldmann applanation tonometer, while CCT was measured by ultrasonic pachymetry. (Compact Touch, Quantel Medical, France).

Each measurement was made in the right eye of each patient within an hour before beginning HD and within one hour after completing a single HD session. To reduce the effects of corneal diurnal variation, we only included morning session HD patients. CCT was obtained by calculating the average of three measurements taken from the central cornea. Body weight was measured before and after HD, and volume loss after HD was calculated.

\section{Statistical analysis}

We performed all statistical analyzes using SPSS software (Version 22.0; SPSS Inc., Chicago, IL, USA). A paired T test was used to evaluate IOP and CCT changes before and after HD. Pearson correlation test was performed to evaluate the correlation between total body volume loss and IOP decrease and CCT decrease. Mann-Whitney test was performed to compare the groups (with DM and non DM). Only the right eyes were analysed. For all results was accepted as statistically significant if $p$ value $<0.05$.

\section{Results}


We examined thirty-four patients in this study.; 22 (64.7\%) were female and 12 (35.3\%) were male. Nineteen of the patients (55.9\%) had DM, while 15 (44.1\%) did not. The mean age was $60.3 \pm 17.2$ (range $21-88)$ years.

Mean dialysis time was $51.4 \pm 38.5$ (range 5-132) months. It was determined that IOP, CCT and body volume reduction were normally distributed ( $p>0.05)$. Mean weight loss after HD $(\mathrm{kg})$ was $1.8 \pm 0.8(95 \%$ $\mathrm{Cl}, 1.53-2.09 ; \mathrm{p} \otimes \mathrm{p}<0.001)$. (0.20-3.70) kg. The mean body volume loss after HD was $2138.2 \pm 921.7$ (95\% Cl, 1816.6-2459.8; $\mathrm{p}<0.001)$ (range 300-4000). (Table 1)

The mean IOP change decreased by $1.76 \pm 1.01 \mathrm{mmHg}$ after $\mathrm{HD}$, from $15.88 \pm 2.37$ to $14.11 \pm 2.02 \mathrm{mmHg}$ $(95 \% \mathrm{Cl}, 1.40-2.11 ; \mathrm{p}<0.001)$ The mean CCT decreased significantly from $554.88 \pm 14.27$ to $550.52 \pm 13.67 \mu \mathrm{m} .(95 \% \mathrm{Cl}, 1.97-4.08 ; \mathrm{p}<0.001)$. (Table 2)

The decreases in IOP and CCT were similar between sexes and DM groups $(p>0.05)$. Body volume loss was significantly correlated with decreased IOP $(r=0.73, p \otimes 0.05$, Fig. 1) and decreased CCT $(r=0.78, p \rrbracket$ 0.05 , Fig. 2). While decreased CCT was positively correlated with the presence of additional disease ( $r=$ $0.29, \mathrm{p} \otimes 0.87)$, decreased IOP was negatively correlated with the presence of additional disease $(r=$ $-0.90, p \otimes 0.61)$.

\section{Discussion}

We found that the IOP and CCT decreased significantly following haemodialysis. Also, mean body volume and weight decreased significantly after haemodialysis.

The kidneys are important to homeostasis as they protect the body fluid electrolyte balance. Therefore, hemodynamic parameters and fluid electrolyte balance are disturbed when kidney failure occurs. We attempt to improve these parameters with haemodialysis. HD may cause changes in plasma colloid osmotic pressure and serum osmolarity, which may affect many systemic parameters.[15]

There are many studies that showing that haemodialysis either increases, decreases, or does not change IOP and/or CCT $[9,16-21]$. The possible causes of lower IOP and CCT after HD are: correcting the amount of excessively accumulated and abnormally dispersed fluid in the body, or increased plasma colloid osmotic pressure. Due to increased plasma colloid pressure, the liquid can flow from the aqueous humus to the plasma. this may lead to a decrease in both IOP and CCT. Some studies have reported that intraocular pressure increases due to increased fluid flow from serum to humour aquosa and impaired fluid output in the trabecular network during HD [22-24].

In our study, After HD, we found a significant decrease in CCT from 554.88 14.27 to $550.52 \pm 13.67$ (95\% $\mathrm{Cl}, 1.9744 .08 ; \mathrm{p}<0.001)$. Similar to our study, although there are studies reporting a decrease in CCT, there are studies reporting that there is no change in CCT[20, 25]

Similarly, to a lot of work done, after HD, we found a significant decrease in IOP from $15.88 \pm 2.37$ to 14.11 $\pm 2.02 \mathrm{mmHg}(95 \% \mathrm{Cl}, 1.40-2.11$; $\mathrm{p}<0.001)$. [19] However, some studies have also reported that IOP 
has increased or remained unchanged after HD. [21, 23]

Also in our study, we detected Body volume loss was significantly correlated with decreased IOP $(r=0.73$, $p \otimes 0.05)$ and decreased CCT $(r=0.78, p \otimes 0.05)$. We found that CCT and IOP decrease were not different according to gender or DM $(p>0.05)$.

Similar to many studies in our study, we measured IOP with applanation tonometry which is the best method. This tonometer is affected by CCT and needs to be corrected according to CCT.[26, 27] IOP measurement by different individuals reported that there may be a reason for the post-HD IOP changes to be reported differently.[28]

In summary, we found that both IOP and CCT significantly and independently decreased regardless of DM and gender after the HD sessions. Therefore, after HD sessions, caution should be exercised in the evaluation of both IOP values and CCT values effecting IOP in patients with CRF. This is important to regulate drug doses used by glaucoma patients and to evaluate IOP measurements affected by CCT [27, $29,30]$.

\section{Conclusions}

While HD corrects the body's fluid electrolyte imbalance due to kidney failure, many ocular parameters, such as IOP and CCT, may change quickly due to changes in the aqueous humour. However, s many studies report very different results for both IOP changes and CCT changes. Therefore, more studies are needed to understand the importance of IOP changes and CCT changes in CRF patients.

\section{Abbreviations}

IOP: Intraocular pressure

CCT: Central corneal thickness

HD: Haemodialysis

CRF: Chronic renal failure

DM: Diabettes Mellitus

\section{Declarations}

\section{Ethics approval and consent to participate}

The study protocol was approved by the ethical research committee of Gazi Yasargil Training and Research Hospital (decision \# 2018/84). Informed consent was obtained from all individual participants 
included in the study. The ethical principles outlined in the Declaration of Helsinki and those of Good Clinical Practice were followed.

\section{Consent for publication}

Not applicable in this study.

\section{Availability of data and materials}

All data generated and analyzed during this study were included in this manuscript.

\section{Competing interests}

The authors declare that they have no competing interests.

\section{Funding}

The study was funded by departmental resources.

\section{Authors' contributions}

SE designed this study. SE and MG collected and analyzed the data and generated the figures. SE and SE involved with the manuscript development and proofreading. SE reviewed and revised the manuscript. SE and $M G$ approved the final version of the manuscript. All authors read and approved the final manuscript.

\section{Acknowledgements}

The authors the technical staff of the ophthalmology and the Dialysis Unit for their help.

\section{Author details}

${ }^{1}$ Department of Ophtalmology, Bismil State Hospital, Bismil, Turkey, ORCID: 0000-0001-5742-1293

${ }^{2}$ Department of Internal Medicine, CInar State Hospital, CInar, Turkey, ORCID:0000-0001-6433-573X

\section{References}

1. Broekema N, Van Bijsterveld OP DBKR (1988) Intraocular pressure during hemodialysis. Ophthalmologica 197:60-64

2. Diaz-Couchoud P, Bordas FD, Garcia JR, et al (2001) Corneal disease in patients with chronic renal insufficiency undergoing hemodialysis. Cornea 20:695-702

3. Charlton JF, Schwab IR, Stuchell R (1996) Tear hyperosmolarity in renal dialysis patients asymptomatic for dry eye. Cornea 15:335-9 
4. Tomazzoli L, De Natale R, Lupo A, Parolini B (2000) Visual acuity disturbances in chronic renal failure. Ophthalmologica 214:403-405.

5. Aktaş Z, Ozdek S, Asli Dinç U, et al (2007) Alterations in ocular surface and corneal thickness in relation to metabolic control in patients with chronic renal failure. Nephrology (Carlton) 12:380-5.

6. Ravelli M, Scaroni P, Mombelloni S, et al (1990) Acute visual disorders in patients on regular dialysis given desferrioxamine as a test. Nephrol Dial Transplant 5:945-949.

7. Niutta A, Spicci D, Barcaroli I (1993) Fluoroangiographic findings in hemodialyzed patients. Ann Ophthalmol 25:375-380

8. Dinc UA, Ozdek S, Aktas Z, et al (2010) Changes in intraocular pressure, and corneal and retinal nerve fiber layer thickness during hemodialysis. Int Ophthalmol 30:337-340.

9. Tawara A, Kobata H, Fujisawa K, et al (1998) Mechanism of intraocular pressure elevation during hemodialysis. Curr Eye Res 17:339-347.

10. Evans RD, Rosner M (2005) Ocular abnormalities associated with advanced kidney disease and hemodialysis. Semin Dial 18:252-257.

11. Song WK, Ha SJ, Yeom HY, et al (2006) Recurrent intraocular pressure elevation during hemodialysis in a patient with neovascular glaucoma. Korean J Ophthalmol 20:109-112.

12. Sati A, Jha A, Moulick P, et al (2016) Corneal Endothelial Alterations in Chronic Renal Failure. Cornea 35:1320-1325

13. Levy J, Tovbin D, Lifshitz T, et al (2005) Intraocular pressure during haemodialysis: A review. Eye 19:1249-1256

14. Austin JN, Klein M, Mishell J, et al (1990) Intraocular pressures during high-flux hemodialysis. Ren Fail 12:109-112.

15. De Marchi S, Cecchin E, Tesio F (1989) Intraocular pressure changes during hemodialysis: Prevention of excessive dialytic rise and development of severe metabolic acidosis following acetazolamide therapy. Ren Fail.

16. Minguela I, Andonegui J, Aurrekoetxea B, De Gauna RR (2000) Prevention of intraocular pressure elevations during hemodialysis. Am J Kidney Dis.

17. Leiba H, Oliver M, Shimshoni M, Bar???Khayim Y (1990) Intraocular pressure fluctuations during regular hemodialysis and ultrafiltration. Acta Ophthalmol.

18. Hu J, Bui KM, Patel KH, et al (2013) Effect of hemodialysis on intraocular pressure and ocular perfusion pressure. JAMA Ophthalmol.

19. Tokuyama T, Ikeda T, Sato K (1998) Effect of plasma colloid osmotic pressure on intraocular pressure during haemodialysis. $\mathrm{Br} \mathrm{J}$ Ophthalmol.

20. Costagliola C, Mastropasqua L (1991) The influence of hemodialysis on intraocular pressure: III. Aqueous humor dynamics and tissue hydration. Ann Ophthalmol

21. Hojs R, Pahor D (1997) Intraocular pressure in chronic renal failure patients treated with maintenance hemodialysis. Ophthalmologica. 
22. Leiba H, Oliver M, Shimshoni M, Bar???Khayim Y (1990) Intraocular pressure fluctuations during regular hemodialysis and ultrafiltration. Acta Ophthalmol.

23. Tovbin D, Belfair N, Shapira S, et al (2002) High postdialysis urea rebound can predict intradialytic increase in intraocular pressure in dialysis patients with lowered intradialytic hemoconcentration. Nephron.

24. De Marchi S, Cecchin E, Tesio F (1989) Intraocular pressure changes during hemodialysis: Prevention of excessive dialytic rise and development of severe metabolic acidosis following acetazolamide therapy. Ren Fail.

25. Diaz-Couchoud P, Bordas FD, Garcia JRF, et al (2001) Corneal Disease in Patients With Chronic Renal Insufficiency Undergoing Hemodialysis. Cornea 20:695-702.

26. Damji KF, Munger R (2000) Influence of central corneal thickness on applanation intraocular pressure. J Glaucoma 9:205-7

27. Doughty MJ, Zaman ML (2000) Human corneal thickness and its impact on intraocular pressure measures: A review and meta-analysis approach. Surv. Ophthalmol.

28. Dielemans I, Vingerling JR, Hofman A, et al (1994) Reliability of intraocular pressure measurement with the Goldmann applanation tonometer in epidemiological studies. Graefe's Arch Clin Exp Ophthalmol.

29. Stodtmeister R (1998) Applanation tonometry and correction according to corneal thickness. Acta Ophthalmol Scand.

30. Shah S, Chatterjee A, Mathai M, et al (1999) Relationship between corneal thickness and measured intraocular pressure in a general ophthalmology clinic. Ophthalmology.

\section{Tables}

Table 1. Demographic data of the patients. 


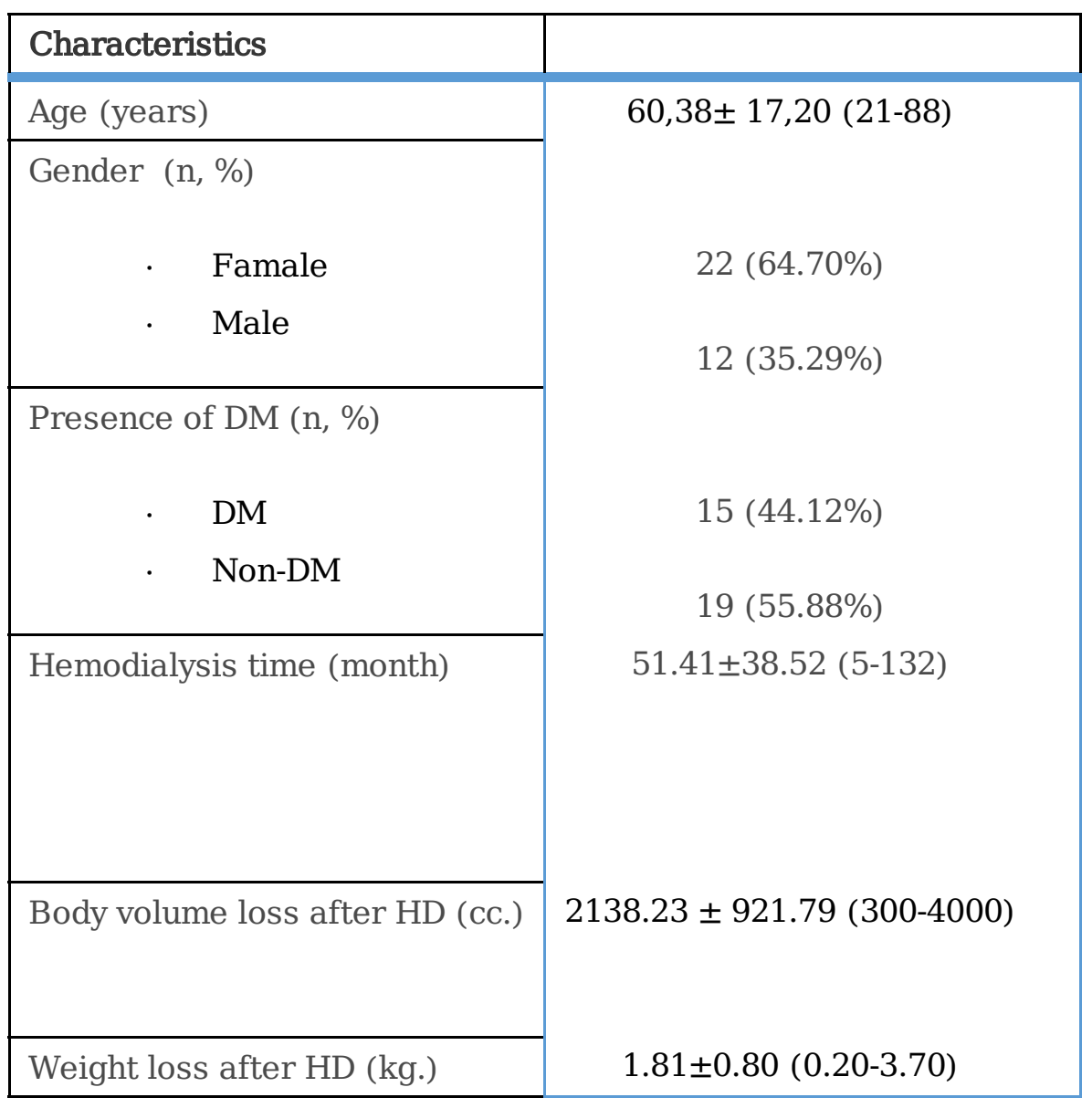

Table 2. The changes of IOP and CCT between before and after HD.

\begin{tabular}{lll}
\hline Characteristics & Intraocular pressure $(\mathrm{mmHg})$ & Central corneal thickness $(\mu \mathrm{m})$ \\
& & \\
\hline Before HD & $15.88 \pm 2.37$ & $554.88 \pm 14.27$ \\
After HD & $14.11 \pm 2.02$ & $550.52 \pm 13.67$ \\
Decrease of after HD & $1.76 \pm 1.01$ & $4.35 \pm 2.22$ \\
$p$ & $<0.05$ & $<0.05$ \\
\hline Total (n) & & $\mathbf{3 4}$ \\
\hline
\end{tabular}

\section{Figures}




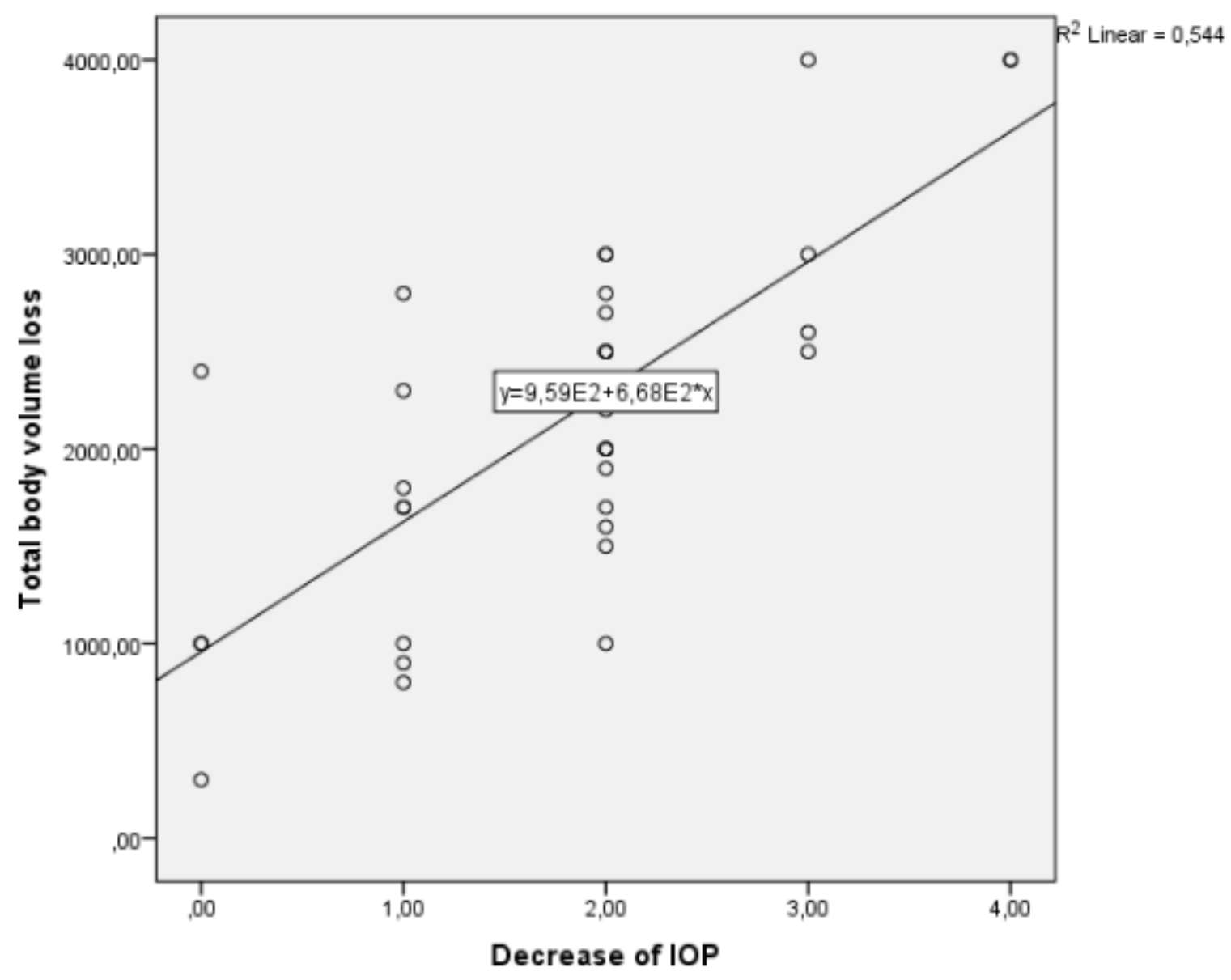

Figure 1

Correlation between total body volüme loss and decrease of intraocular pressure. 


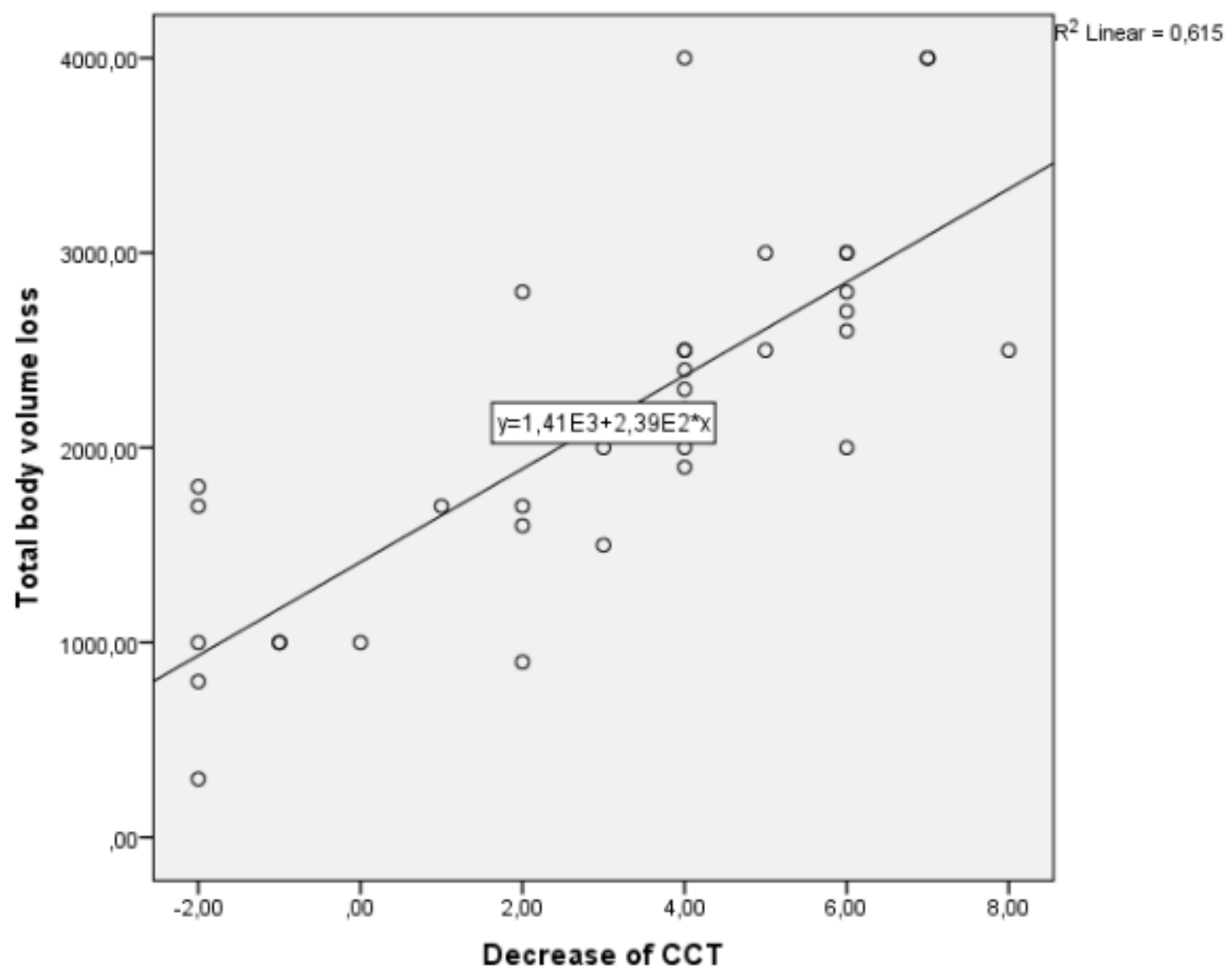

Figure 2

Correlation between total body volüme loss and decrease of central corneal thickness. 